\title{
RELACIONAMENTO INTERORGANIZACIONAL COOPETITIVO NA INDÚSTRIA AUTOMOBILÍSTICA BRASILEIRA
}

\section{COOPETITIVE INTERORGANIZATIONAL RELATIONSHIP IN BRAZILIAN AUTOMOBILE INDUSTRY}

\section{Hellen Claudia Donato}

Universidade Municipal de São Caetano do Sul, Doutoranda em Administração pelo Programa de Pós-Graduação em Administração da USCS São Caetano do Sul, SP, Brasil

Email: hellen.claudia@hotmail.com

\section{Luiz Celso Peretti}

Universidade Municipal de São Caetano do Sul, Doutorando em Administração pelo Programa de Pós-Graduação em Administração da USCS São Caetano do Sul, SP, Brasil

Email: luizcelsoperetti@gmail.com

\section{Ana Cristina de Faria}

Universidade Nove de Julho, Pós-Doutorado em Gestão de Operações e Logística pela FGV-SP, Doutora em Controladoria e Contabilidade pela USP, Docente do Programa de Mestrado Profissional em Gestão Ambiental e Sustentabilidade - PMP-GeAS da Uninove

São Paulo, SP, Brasil

Email: anacfaria@uol.com.br

\section{Luciane Ribeiro Dias Pinheiro}

Universidade Municipal de São Caetano do Sul - USCS, Doutoranda em Administração pelo Programa de Pós-Graduação em Administração da USCS

São Caetano do Sul, SP, Brasil

Email: dias.luciane@ig.com.br

\section{Marcos Antonio Gaspar}

Universidade Nove de Julho, Doutor em Administração pela USP, Professor do Programa de Pós-Graduação em Informática e Gestão do

Conhecimento

São Paulo, SP, Brasil

Email: marcos.antonio@uninove.br

\section{Milton Carlos Farina}

Universidade Municipal de São Caetano do Sul - USCS, Doutor em Administração pela FEA-USP, Docente do Programa de Pós-Graduação em Administração da USCS

São Caetano do Sul, SP, Brasil

Email: milton_farina@uol.com.br

\section{RESUMO}

O objetivo deste trabalho é analisar a existência de coopetição entre empresas no processo de implantação do projeto do Agente Redutor de Óxidos de Nitrogênio (NOx) Automotivo (Arla 32) na indústria automobilística brasileira. Esta é uma pesquisa descritiva qualitativa levada a cabo por meio da aplicação de roteiro de entrevistas semiestruturado e análise documental. A técnica de análise de conteúdo foi aplicada buscando-se identificar as ações de coopetição desenvolvidas pelas empresas, conforme os fundamentos propostos na teoria da coopetição em relacionamentos interorganizacionais entre empresas atuantes em redes de negócios. Os resultados da pesquisa levaram à constatação da ocorrência de ações de cooperação entre as empresas competidoras na rede de negócios voltada à produção e distribuição do produto no País. Foram verificadas ações de auxílio quanto à infraestrutura, tecnologia, pessoas e atividades complementares em parceria, todas desenvolvidas a partir de um objetivo comum, a implantação do produto no Brasil. Houve ainda o diagnóstico da coopetição no desenvolvimento de embalagens e na distribuição e, principalmente, na definição de atuação de cada empresa no mercado como competidoras diretas. Assim, utilizando-se o agente redutor Arla 32, cada empresa com seu posicionamento de marca específico no mesmo ambiente competitivo em comum, foi possível o atendimento do mesmo público-alvo prospectado pelos concorrentes.

Palavras-chave: Coopetição. Indústria automobilística. Relacionamento interorganizacional. Rede de negócios. Arla 32.

Data de submissão: 6 de fevereiro de 2016.

\section{ABSTRACT}

This research aims to analyze the existence of coopetition between companies in the process of implementation of the project of the automotive reducer agent of nitrogen oxides (NOx) - Arla 32 in the Brazilian automobile industry. This is a qualitative descriptive research that applied a semi-structured interview script and documentary analysis. The technique of content analysis was applied seeking to identify the actions of coopetition developed by the companies involved, according to the fundamentals proposed in the theory of coopetition in interorganizational relationships between companies working in business networks. The results led to the observation of the occurrence of cooperative actions among the competing companies in the business network geared to the production and distribution of the product (Arla 32) in the country. Assistance actions were verified regarding to infrastructure, technology, people and complementary activities in partnership, all them developed from a common goal, the implantation of the product in Brazil. There was also the diagnosis of coopetition in the development of packaging and distribution and, mainly, in the definition of each company's performance in the market as direct competitors. Thus, using the reducer agent Arla 32, each company with its specific brand positioning in the same competitive environment, it was possible to attend the same target audience prospected by competitors

Keywords: Automotive industry. Business network. Coopetition. Interorganizational relationships. Arla 32.

Data de aprovação: 28 de setembro de 2019. 


\section{INTRODUÇÃO}

Os relacionamentos interorganizacionais perfazem um tema de crescente interesse, que tem sido mais bem analisado ao redor do mundo em diversos segmentos nos últimos anos, tais como no setor automobilístico e de informática, entre outros. Neste trabalho, os relacionamentos interorganizacionais são apresentados por meio de alianças estratégicas entre empresas, com o uso da cooperação num ambiente competitivo, visando à obtenção de melhores resultados aos envolvidos, bem como reposicionamento de mercado e até a inclusão de novos produtos ou melhoria nos processos, procedimentos e qualidade de produtos já existentes (HITT; IRELAND; HOSKISSON, 2002).

Inclui-se neste fenômeno o lançamento, produção e distribuição do produto Agente Redutor de Óxidos de Nitrogênio (NOx) Automotivo - Arla 32, que é conhecido e ingressou no Brasil em 2012 como um agente redutor líquido de nox automotivo. Trata-se de uma solução aquosa não tóxica de ureia técnica, desenvolvida para a redução da emissão de poluentes na atmosfera, que se originou para atender à Resolução do Conselho Nacional do Meio Ambiente - CONAMA n. ${ }^{\circ}$ 403, de 11 de novembro de 2008, por meio do Programa de Controle da Poluição do Ar Veículos Automotores PROCONVE.

Para atender a resolução exposta, atualmente aplicada em ônibus e caminhões que utilizam o diesel S50 e S10, houve a necessidade da adaptação das empresas que estão nesse mercado ou que pretendem atuar nele. Ao perceberem essas novas oportunidades de negócios, as empresas da indústria de combustíveis buscaram preparar-se para a competição desse novo produto no mercado nacional.

Assim, as montadoras incluíram em seus motores um catalisador, que é exigido nos novos caminhões desde janeiro de 2012, equipamento destinado ao tratamento dos poluentes resultantes da combustão do diesel em veículos pesados. Isso porque o processo de queima de combustível emite dióxido de carbono $\left(\mathrm{CO}_{2}\right)$, o que contribui para o efeito estufa.

Essa nova configuração de mercado proporcionou a reorganização das cadeias produtiva e de distribuição, com a necessidade de novos relacionamentos interorganizacionais a fim de viabilizar estratégias para operar o produto Arla 32 com o novo catalisador. Esse fato proporcionou o relacionamento entre diferentes empresas focadas nessa cadeia produtiva, uma vez que o foco era implantar esse produto no País e atender a demanda dos consumidores por meio de um agente redutor (Arla 32). Destaca-se a atratividade do novo negócio, pois o mercado em questão apresenta crescimento contínuo de aproximadamente $5 \%$ da utilização do diesel (ANFAVEA, 2014).

Não obstante, há de considerar-se que, para a implantação desse produto, há necessidade da formação de parcerias entre empresas de diferentes setores, que atuam também como competidores diretos em determinados mercados. Como exemplo, destaca-se a existência de bandeiras diferentes dos postos de gasolina os quais, por sua vez, são fornecedores tanto de diesel, quanto de agente redutor, as montadoras de caminhões e ainda as empresas de distribuição.

Nesse sentido, insere-se no problema o conceito de coopetição, com ocorrência da cooperação e da competição (BRANDENBURGER; NALEBUFF, 1996), pois apresentam-se, também, os relacionamentos interorganizacionais entre os agentes envolvidos com o desenvolvimento de estratégia de posicionamento de marca, mesmo que seja com a utilização do mesmo produto (Arla 32), num ambiente competitivo com o objetivo de ganhos mútuos entre os participantes, visando ao desenvolvimento do mercado neste momento inicial.

Diante do exposto, o problema que norteia esta pesquisa é: Como tem sido feita a implantação do projeto do Agente Redutor de Óxidos de Nitrogênio (NOx) Automotivo - Arla 32 na indústria automobilística brasileira, com foco no 
desenvolvimento de relacionamentos interorganizacionais, amparados no conceito da coopetição (cooperação e competição) como estratégia das empresas participantes?

Este trabalho tem como objetivo verificar a existência de coopetição entre empresas no processo de implantação do projeto do Agente Redutor de Óxidos de Nitrogênio (NOx) Automotivo - Arla 32 na indústria automobilística brasileira. Como complemento, apresentam-se ainda os seguintes objetivos específicos: mapear as empresas atuantes na produção e distribuição do Arla 32 e identificar como ocorre a cooperação entre as empresas concorrentes atuantes (coopetição) no desenvolvimento e distribuição do referido produto.

\section{REFERENCIAL TEÓRICO}

\section{Redes de Negócios}

Há mais de duas décadas, muitos trabalhos têm sido destacados sobre o tema redes de negócios. Autores como Miles e Snow (1986) são destaques em trabalhos sobre a formação de organizações que atuam em redes, enfatizando os fundamentos deste novo estudo acadêmico na formação das organizações das empresas.

Conforme Rodrigues, Maccari e Riscarolli (2007), desde o início da década de 1990, diversas pesquisas têm sido publicadas sobre o assunto, tais como os trabalhos de Perrow (1992), Lipnack e Stamps (1994), Quinn et al. (1996), Castells (1999), Cândido e Abreu (2000), Casarotto e Pires (2001), Hoffmann et al. (2004) e Verschoore e Balestrin (2008; 2010).

Nas redes interorganizacionais, conforme Castro, Bulgacov e Hoffmann (2011), há evidências de uma dinâmica que tem sido apresentada em inúmeros trabalhos resultantes dos conceitos de cooperação e competição. Na abordagem do tema competição, emergiu a questão das interações entre empresas que atuam em redes, isto é, são concorrentes, mas ao mesmo tempo cooperam entre si, no intuito de atingir objetivos comuns. Os relacionamentos são cooperativos e o comportamento é o de competição entre as organizações (GNYAWALI; MADHAVAN, 2001; GIMENO, 2004; REINL; KELLIHER, 2010; MONTICELLI; SILVEIRA; SILVA, 2018).

A rede de empresas é "um conjunto de empresas entrelaçadas por relacionamentos formais ou simplesmente negociais, podendo ou não ser circunscritos a uma região" (CASAROTTO; PIRES, 2001, p.87). Verificam-se vários tipos de relacionamentos entre as empresas, tais como as alianças estratégicas, distritos industriais e consórcios, além de redes de cooperação (BALESTRIN; VARGAS, 2004). Na visão de Humphrey e Schmitz (1998), as redes de empresas oferecem meios para as empresas crescerem e competirem. Resende et al. (2017) indicam que a criação de redes de negócios reúne empresas de um mesmo setor com o objetivo de solucionar limitações comuns, que o processo de criação deve levar em conta, as necessidades e objetivos da rede e que deve haver critério na seleção dos parceiros. Os autores confirmam que, entre outros fatores, a confiança e a governança são importantes para a manutenção da rede de negócios.

Em complemento, Verschoore e Balestrin (2008, p.2) apontam que o desenvolvimento de atividades em rede onde ocorre a cooperação, gera ganhos competitivos às empresas participantes: "provisão de soluções; ganhos de escala e de poder de mercado; aprendizagem e inovação; relações sociais; e redução de custos e riscos". Tais ganhos competitivos, na visão dos referidos autores, são aplicados na parceria entre as empresas para o desenvolvimento de ações que proporcionam benefícios oferecidos aos participantes da rede.

Pereira et al. (2018) pesquisaram o tema redes de cooperação tecnológica no campo da biotecnologia e enfatizaram que mesmo instituições com alta capacidade de inovação poderiam utilizar melhor suas habilidades 
estabelecendo cooperação com outras organizações. Sacomano Neto e Truzzi (2002), complementando o raciocínio exposto, destacam que as redes são constituídas pela cooperação entre empresas e que podem mostrar-se com vínculos fortes. Essas relações ocorrem por meio da confiança que, por sua vez, possibilita o compartilhamento das informações, de forma recíproca, para fortalecer as inter-relações dos atores da rede.

Dessa maneira, ao verificar as redes de cooperação, Machado Filho e Zylbersztajn (2004) afirmaram que a eficiência está fundamentada no estabelecimento de confiança, comprometimento e cooperação entre as empresas participantes da rede. Zaccarelli (2005) defende a ideia de fidelidade e reciprocidade, frisando que a rede deva ser uma unidade competitiva maior que a soma de seus participantes isoladamente.

A cooperação e o comprometimento influenciam a cooperação entre empresas, porém Chen, Chen e Whu (2017) enfatizam que há um efeito mediador dos investimentos em ativos na relação entre esses conceitos e o valor do relacionamento que ocorrem entre cliente e fornecedor. Nesse contexto, segundo Santos et al. (1994), existem dois tipos de rede de cooperação interempresariais: as redes verticais como a de uma cadeia produtiva e as horizontais, nas quais as empresas são de determinado setor e podem ser concorrentes entre si, mas que sozinhas encontram dificuldade para adquirir recursos para as suas próprias atividades.

As redes de cooperação são aplicadas separadamente ou em conjunto pelas empresas, com o objetivo de melhoria contínua nos processos, procedimentos, reposicionamento estratégico e até para sobrevivência no mercado competitivo atual. Entretanto apresentam-se, também na literatura, paradigmas sobre o tema redes, tais como:

- o primeiro paradigma trata dos temas de ordem econômica e da racionalidade que influem na participação numa rede de empresas, com base na teoria das escolhas limitadas, dos custos de transação e teoria dos jogos (WILLIAMSON, 1985; CLEMENT, 1994);

- o segundo paradigma trata dos aspectos de ordem social, influenciadores nas relações entre as empresas da rede. Encontram-se nessa vertente as teorias sobre governança, imersão social e conflitos de interesse dos atores participantes (UZZI, 1997; ROWLEY, 1997);

- o terceiro paradigma valoriza uma estrutura social diferenciada (sociedade em redes); este último ainda não é totalmente reconhecido como paradigma, mas é muito citado por diversos autores. Trata das teorias da ação coletiva de grandes grupos, nas quais são importantes os sentimentos e crenças comuns em que se condissera o conjunto das crenças e dos sentimentos comuns que conferem uma vida própria ao sistema (OLSON, 1971; WEBER, 1982; MATURANA, VARELA, 1987).

Esses paradigmas remetem à ideia de cooperação entre empresas, com o objetivo de ganhos mútuos aos participantes, independente do segmento em que estão insertos, por meio de alianças estratégicas que ocorrem entre parceiros e/ou concorrentes, quando as limitações e os benefícios compartilhados compensam o confronto entre as estratégias cooperativas e competitivas.

O objetivo é alcançar níveis diferenciados de competitividade baseados nas estratégias de cooperação resultantes das relações entre as empresas. Gulati (1998), Cassiolato e Lastres (1999) e Afhuja (2002) enfatizam que o gerador de vantagens competitivas é a interação que ocorre entre as empresas da rede.

A cooperação nas redes de empresas é importante para que haja um ambiente tecnológico e processos de inovação dinâmicos, os quais contribuem para o sucesso das organizações em rede (FREEMAN, 1988; HAGEDOORN, 2002). 
Dessa forma, a inovação torna-se uma fonte de vantagem competitiva e a estratégia de coopetição contribui para o crescimento das empresas em seus negócios. A cooperação permite o acesso a novos conhecimentos. A atuação em rede favorece a maior aprendizagem, novas tecnologias ampliam a capacidade tecnológica e o processo de inovação (JORDE; TEECE, 1989).

Nesse novo contexto, encontram-se as redes interorganizacionais que Verschoore (2004) define como uma organização em forma de arranjo, composta por um grupo de empresas que são concorrentes e, ao mesmo tempo, cooperam por objetivos comuns. Com isso, as organizações vêm transformando seu modelo organizacional para adaptarse às condições de incerteza impostas pela rápida transformação econômica propagada por Castells (1999).

Somando-se a isso, Gulati, Nohria e Zaheer (2000) afirmam que a luta entre atores, competindo uns contra outros por lucro, está cada vez menos adequada à atual sociedade regida por relacionamentos. Assim, a cooperação por meio de arranjos entre as empresas na formatação de redes de negócios é estratégica ao posicionamento, estabilidade e sobrevivência no mercado competitivo contemporâneo.

\section{Estratégias de Coopetição no relacionamento inteorganizacional}

Ao abordar a estratégia de coopetição por meio de relacionamentos interorganizacionais, sugere-se a possibilidade de que concorrentes cooperem entre si para analisar recursos e capacidades com base na parceria entre as empresas, para gerar vantagens competitivas para elas (HITT; IRELAND; HOSKISSON, 2002). Essa nova estratégia adotada no mercado competitivo foi denominada de coopetição, por Brandenburg e Nalebuff (1996), resultante da atuação de cooperação e de competição simultâneas. Leão (2005) indica que a cooperação entre concorrentes é a forma de se compreender a coopetição.

A coopetição, para Dagnino e Padula (2002), é um novo enfoque de estudo para a dinâmica da interdependência entre empresas que atuam em rede. O que ocorre é uma relativa convergência entre os objetivos das empresas que pode resultar na criação de valor. Numa rede de empresas, a coopetição induz a construção de estratégias de negócios com base na cooperação e na competição entre elas para criar maior valor para o mercado.

Assim, a coopetição é uma abordagem moderna segundo Brandenburger e Nalebuff (1996) por apresentar maior similaridade com as situações que o mercado impõe, pois em alguns momentos as empresas competem entre si e, em outros, elas colaboram entre si.

Dessa forma retira-se o foco da competição. A literatura apresenta muitos trabalhos a respeito da concorrência entre as empresas e não apenas ignora os relacionamentos que ocorrem entre elas, como também como o mercado se expande e as novas formas mais criativas de negócios (BRANDENBURGER; NALEBUFF, 1996; ARMSTRONG, 1997; HITT; IRELAND; HOSKISSON, 2002; CHIEN; PENG, 2005).

No entanto a cooperação contribui para o surgimento e a mudança de novos negócios por meio das parcerias visando ganhos mútuos, apesar de que podem ocorrer as incertezas e oportunismos dos envolvidos, devido à competição e às mudanças das estratégias ou à falta de cooperação.

A cooperação ocorre de várias formas tais como alianças, parcerias e redes de negócios na busca de conhecimentos e de recursos que, segundo Grant (1991), leva à criação e conquista de vantagens competitivas para a empresa.

Tais vantagens competitivas ocorrem por acordos formais, nas alianças estratégicas ou por acordos informais, que têm base na confiança e normas sociais (BENGTSSON; KOCK, 2000) entre os participantes. O envolvimento na 
cooperação ditará o sucesso desse tipo de parceria. Deve ser salientado que a confiança mútua entre as partes determina o sucesso da estratégia de cooperação, sua própria aprendizagem e o bom relacionamento (BENGTSSON; KOCK, 2002). Ressalta-se que podem existir riscos inerentes à coopetição (LEÃO, 2005).

$\mathrm{Na}$ visão de Begnis, Pedrozo e Estivalete (2005), a cooperação surge das várias formas dos arranjos interorganizacionais: nas cadeias de produção, suprimentos, nos clusters e redes de negócios, entre outros.

Nesses arranjos formam-se vínculos entre os vários agentes do determinado território como as empresas que produzem, fornecem serviços, as que comercializam por meio de cooperativas ou outras formas de associação, organizações privadas e também públicas. Outros agentes seriam as empresas de consultoria, recursos humanos, financiamento e de engenharia (BITTENCOURT, 2015).

Leão (2005) ressalta que o nível de competição entre as empresas é fator indicador do desenvolvimento de novas tecnologias e produtos. A competição contribui para a inovação que as empresas buscam como forma de se diferenciar e receber maiores ganhos quando comparadas com as empresas que não fazem parte da rede. Pode-se propor que alto grau de inovação num setor da indústria é sinal de alta competição entre as empresas que participam da rede.

Para Hitt, Ireland e Hoskisson (2002), essa competição ativa tem origem no conjunto de ações e de respostas que ocorrem entre as empresas. $\mathrm{O}$ aumento da competição, em conjunção com a velocidade das transformações tecnológicas, provoca a alteração dos fatores de produção e da lógica de relações empresa-cliente.

Esse ambiente turbulento de negócios, em que a incerteza se transformou em variável-chave no vocabulário de qualquer empresa contemporânea, fez com que o direcionamento de estudos migrasse da lógica do paradigma clássico de ganha-perde de empresas independentes, para uma lógica cooperativa, de relações do tipo ganha-ganha de empresas insertas em redes de cooperação (BRANDENBURGER; NALEBUFF, 1996; BENGTSSON; KOCK, 2000; WANG; KRAKOVER, 2008).

Afuah (2000) pesquisou e avaliou as capacitações das empresas que competem e cooperam entre si no desenvolvimento de processo de mudança tecnológica. Além da perda da vantagem competitiva numa mudança de tecnologia, a empresa que não coopera pode também perder essa capacitação, ou ficar obsoleta entre as empresas competidoras. O autor ressalta a necessidade de se ter visão dos recursos e da gestão deles, tanto no âmbito de cada empresa quanto no conjunto inteiro das empresas.

A adequada utilização das estratégias para cooperar e competir contribui para o sucesso das empresas. A cooperação possibilita o uso dos ativos e a tensão criativa contribui para a competição (LEÃO, 2005). Leão ressalta também a existência de poucos estudos a respeito do beneficiamento que ocorre com as estratégias simultâneas de cooperação e competição. Dessa forma existe a necessidade de os estudos levarem em conta as duas estratégias. $\mathrm{Na}$ coopetição, as empresas cooperam e competem entre si e progridem no processo. As relações desse processo não têm formato nem ciclo definidos e baseiam-se nos relacionamentos que ocorrem entre os diversos atores (BENGTSSON; KOCK, 2000).

A Coopetição pode ser definida como um relacionamento diádico e de certa forma paradoxal, que surge quando duas empresas cooperam em certos momentos em determinadas atividades e competem no mercado (BENGTSSON; KOCK, 2000). Em complemento, Bengtsson e Kock comentam que os relacionamentos coopetitivos são complexos, porque consistem em duas lógicas de interação diferentes: de um lado hostilidade e interesses conflitantes e, de outro, amizade e interesses comuns. Para Dagnino e Padula (2002), a coopetição gera uma relação de interdependência entre as empresas. 
Em complemento, Brandenburger e Nalebuff (1996) abordam a coopetição como uma rede de valores: as empresas podem ter benefícios quando se relacionam com as outras empresas competidoras com base não apenas na competição e na cooperação, mas também nos fatores relativos ao conceito da complementaridade. Isso acaba por diversificar os papéis dos gestores, o que possibilita a criação de estratégias de negócios, com incremento de competitividade na oferta de produtos, serviços e tecnologias (GHEMAWAT, 2002).

Considera-se criticamente que falta ao conceito de coopetição não apenas precisão, mas também um referencial de valores que o sustente, para que possa alçar um patamar heurístico para práticas ou modelos de gestão, atualmente em voga. Na visão de Gulati, Nohria e Zaheer (2000), empresas com perfis similares tornam-se equivalentes em termos de estrutura, o que as relaciona independentemente quanto à formalização entre si, levando-se em consideração as diversas empresas envolvidas, a estratégia em foco no âmbito organizacional (que trata dos recursos e resultados internos) e no interorganizacional (que se refere àquelas desenvolvidas entre duas ou mais organizações), conforme asseveram Jaoen e Gundolf (2009).

Mediante o exposto, identifica-se nas teorias apresentadas que, no ambiente corporativo, o ingresso em redes de negócios com o desenvolvimento de relacionamentos interorganizacionais de coopetição propõe às empresas envolvidas o acesso a: novos mercados, ocupação da capacidade ociosa, melhoria nos processos e procedimentos, aprendizado, compartilhamento de informações, infraestrutura, pessoas, tecnologia e inovação, entre outros benefícios, de acordo com o objetivo proposto pela estratégia organizacional.

$\mathrm{Na}$ busca de recursos ou capacidades, as empresas tendem a se apoiar nos fornecedores, clientes e concorrentes para se engajar em parcerias ou em estratégias de coopetição para ter acesso a eles; o modo como lidar com esses recursos e capacidades também é importante e apresenta desafios para acumular, mobilizar e implantar (BOUNCKEN et al., 2015).

\section{MÉTODO E MATERIAIS}

Esta é uma pesquisa de natureza descritiva e de abordagem qualitativa (GIL, 2002), uma vez que se descreve o fenômeno da formação de relacionamentos interorganizacionais em rede de negócios para a viabilização do produto Arla 32 no País. Trivinos (1987, p. 110) assevera que "conhecer a comunidade, seus traços característicos, gentes, problemas e valores" são ações típicas de estudos descritivos qualitativos.

Ao coletar dados sobre os questionamentos que surgem ao se explorar o fenômeno em estudo, é possível definir o que investigar, conforme indicam Sampieri, Collado e Lucio (2013). Em complemento, é possível descrever as situações de mercado a partir dos dados primários com o uso de ferramentas como entrevistas semiestruturadas, questionários e observações diretas (MICHEL, 2009).

As empresas selecionadas nesta pesquisa, doravante nominadas $A, B$ e $C$, são as maiores e mais representativas da rede de negócios considerada para a instituição do Arla 32 no País. As empresas A, B e C atuam nos segmentos de agronegócio, químico e petroquímico.

As empresas não foram identificadas nesta pesquisa, devido ao acordo preestabelecido de não divulgação dos nomes dos responsáveis e respectivas empresas envolvidas no desenvolvimento e implantação do projeto citado, dado seu caráter estratégico. Cabe destacar que a Empresa A é a líder global de fornecimento de fertilizantes e produtos industriais nitrogenados. Já a Empresa B é produtora e líder na distribuição do Arla 32 e do diesel S50. Por fim, a Empresa C é a maior produtora desse produto no Brasil. 
Os dados primários foram coletados por meio de entrevistas semiestruturadas realizadas com gestores das três empresas mais proeminentes atuantes na rede de negócios considerada. Os respondentes das empresas são gestores comerciais responsáveis pela área de projeto e desenvolvimento de novos produtos. Todos os gestores respondentes da pesquisa de campo executada têm nível superior completo, com formação em Engenharia. O tempo médio de atuação na área destes profissionais é de 12 anos e o tempo médio de atuação na empresa é de 5 anos.

As respostas às perguntas do roteiro semiestruturado de entrevistas aplicado foram transcritas para aplicação da técnica de análise de conteúdo de Bardin (2011), buscando-se identificar conteúdos nas falas dos respondentes que sinalizassem possíveis categorias de análise a serem consideradas na pesquisa. Assim, os conteúdos identificados foram submetidos à técnica de análise de conteúdo com base nos fundamentos propostos na teoria da coopetição, bem como no referencial teórico voltado aos relacionamentos interorganizacionais entre empresas atuantes em redes de negócios.

A pesquisa documental ocorreu por meio de dados obtidos nos sites das empresas, órgãos competentes e fórum focado no projeto do Arla 32, os quais não foram citados nominalmente nesta pesquisa, devido à questão de confidencialidade das informações tratadas.

\section{DESCRIÇÃO E ANÁLISE DOS RESULTADOS}

A análise qualitativa dos resultados baseou-se na proposta metodológica para nortear este estudo, buscando elucidar aspectos sobre os principais fatores que influenciam o relacionamento interorganizacional coopetitivo em redes de negócios. Para o melhor entendimento do fenômeno em estudo, foram mapeadas as empresas atuantes na produção e distribuição do Agente Redutor de Óxidos de Nitrogênio (NOx) Automotivo - Arla 32, o que já atende ao primeiro objetivo específico, além de descrever como ocorre a implantação do referido produto no Brasil, visando atingir o objetivo geral que é o de verificar a existência de coopetição entre empresas no processo de implantação do Arla 32 na indústria automobilística brasileira.

Conforme o relato dos respondentes, a Empresa A é considerada a líder global de fornecimento de fertilizantes e produtos industriais nitrogenados. Sua perspectiva é de ampla disponibilidade de produto no mercado, iniciando para tanto o processo com produtos embalados, porém com estratégia futura focada no fornecimento a granel.

A Empresa B, de acordo com as respostas dos entrevistados, é produtora e líder na distribuição do Arla 32 e do diesel S50 no Brasil. Sua perspectiva prevê investimento em infraestrutura para melhor distribuir o produto, aproveitando assim sua cadeia já consolidada nos postos de combustíveis.

A Empresa $C$ foi citada por todos os entrevistados como a maior fabricante desse produto no Brasil. É a fornecedora do produto Arla 32 para outros distribuidores que atuam no segmento de postos de combustíveis e com a cooperação de empresas responsáveis pelo envase e até distribuição do produto em embalagens.

Com isso, responde-se ao segundo objetivo específico que buscava identificar como ocorre a cooperação entre as empresas atuantes no desenvolvimento e distribuição do Arla 32. Ao mapear as empresas envolvidas na rede de cooperação instituída, constata-se nas informações relatadas pelos respondentes que há somente dois produtores no Brasil, sendo esses as empresas denominadas neste estudo como B e C, fornecedoras dele para outras empresas que, no segmento de combustíveis, são concorrentes diretas.

O Agente Redutor de Óxidos de Nitrogênio (NOx) Automotivo (Arla 32) é conhecido como ureia técnica utilizada com fertilizante, coadjuvante na alimentação animal, com aplicações em plástico, resina, estabilizante de explosivo, na área médica, em adesivos, sequestrante no tratamento de efluentes e, ainda, agente contra incêndio, além da utilização 
na fabricação de cosméticos e alguns tipos de detergente.

Por isso não é nocivo ao meio ambiente, apresentando-se como uma solução aquosa solúvel em água e álcool. Sua nomenclatura é composta pelo número 32 devido à sua concentração em peso. A sua principal função é reduzir a emissão de poluentes na atmosfera, alterando os gases de combustão, em parceira com uma tecnologia implantada nos motores dos veículos pesados (elemento catalisador do processo de combustão).

Para que esse processo ocorra, foram estudadas duas alternativas para atender a legislação. A primeira com o desenvolvimento de nova tecnologia do motor a diesel. A segunda com utilização da tecnologia Euro $V$, que é o uso do Arla 32 + redução catalítica seletiva (SCR - Selective Catalytic Reduction), foco do estudo nesta pesquisa. Essa tecnologia exige dos veículos serem abastecidos com óleo diesel que contenha baixo teor de enxofre (S50 ou S10); o combustível é pulverizado no escapamento dos caminhões e ônibus por meio de um catalisador (SCR), antes de ser ejetado para converter os gases de combustão em vapor de água em nitrogênio, conforme exposto na Figura 1.

Figura 1: Funcionamento do sistema SCR e ureia técnica

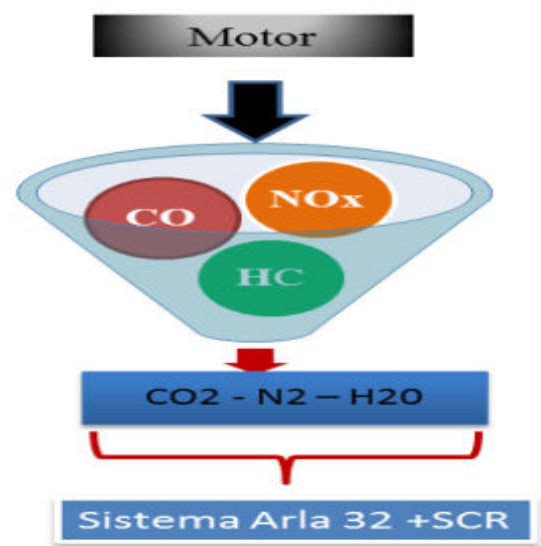

Fonte: Elaborada pelos autores.

Na Figura 1 apresenta-se o funcionamento da conversão dos gases de combustão em vapor, por meio do sistema SCR e da ureia técnica, com a transformação das emissões de Monóxido de Carbono, Nox e Hidrocarbonetos em Dióxido de Carbono, Nitrogênio e vapor d'água. Esse processo, bem como o desenvolvimento do produto Arla 32 e da tecnologia SCR, foi criado em função da Resolução CONAMA n. ${ }^{\circ} 403$ e do Programa de Controle da Poluição do Ar por Veículos Automotores - PROCONVE (2013), que determinam reduções nos níveis de emissões de poluentes de veículos a diesel. A Figura 2 exibe resumidamente o esquema de funcionamento do Arla 32. 
Figura 2: Funcionamento do Arla 32 do motor até a atmosfera

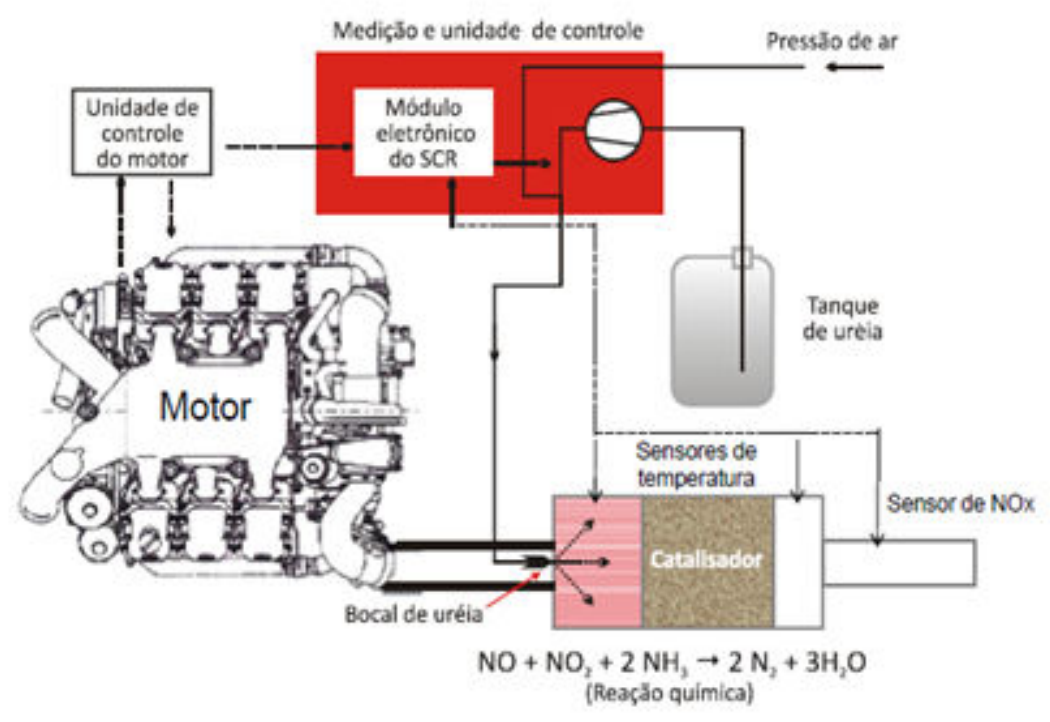

Fonte: Elaborada pelos autores.

De acordo com os respondentes da pesquisa de campo, esse sistema foi analisado internacionalmente, com a aplicação dessa tecnologia no Japão em 2005, na Europa em 2006 e na Áustria em 2008, bem como sua entrada nos Estados Unidos em 2008 e na China em 2010. Constitui-se na única tecnologia disponível para atender o Euro V com redução de poluição e tanques segregados nos veículos, ou seja, um recipiente para o combustível e outro para o agente redutor.

Neste período de análise, foi identificado que o Arla 32 equivale a, aproximadamente, $5 \%$ do consumo do diesel, e desenvolvida uma proposta para sua cadeia de distribuição. A análise foi efetuada com base no funcionamento da implantação do produto na Europa, levando-se em consideração a parceria entre os produtores, distribuidores, montadoras, postos de combustível e consumidores finais, caracteriza-se como um exemplo de coopetição.

Os respondentes informaram que, atualmente, sua distribuição é realizada de maneira embalada e/ou a granel. Houve evolução de sua oferta nos postos de combustíveis, com crescimento contínuo na utilização do agente redutor, fato que direcionou este modelo para ser aplicado na implantação e desenvolvimento desse produto no Brasil.

Visto isso, é relevante descrever que esse processo se iniciou com experiências das montadoras realizando testespilotos com a inclusão da tecnologia nos motores dos caminhões, caracterizando, assim, a ocorrência de redes de cooperação envolvendo diferentes agentes do processo produtivo (PERROW, 1992; LIPNACK; STAMPS, 1994; HUMPHREY; SCHMITZ 1998; QUINN et al. 1996; COCCO, 1998; CÂNDIDO; ABREU, 2000; HOFFMANN et al., 2004; BALESTRIN;VARGAS, 2004 ).

Em complemento, a Empresa A identificou que há escassez de ureia técnica para a fabricação desse produto, o que gerou a oportunidade de se pensar sobre como o produto chegaria até os consumidores, e qual garantia de qualidade seria ofertada a eles. Entre as análises realizadas, identificou-se a possibilidade de, inicialmente, importar o produto da Europa, visando ao abastecimento do processo produtivo a se desenvolver no País.

Esses questionamentos e a necessidade de concorrentes atuarem em parceria, num exemplo de coopetição, para atender o mercado, remeteram às respostas dos objetivos propostos, iniciando-se com o mapeamento de quais empresas 
atuam no desenvolvimento e na distribuição do Arla 32. Em resposta, definiu-se trabalhar com as três principais empresas que lideram o projeto, descritas neste estudo como Empresa A, B e C, conforme explicitado no capítulo de método e materiais.

Com base nos fatos relatados pelas empresas analisadas, demonstra-se a aplicação das características da teoria da coopetição, notadamente a simultaneidade da cooperação e da competição buscando o estabelecimento de parcerias com ganhos mútuos, conforme apregoam autores como Brandenburger; Nalebuff (1996); Lado; Boyd; Hanlon (1997); Bengtsson; Kock (2000); Leão (2005); Gnyawali (2006) e Wang; Krakover (2008).

$\mathrm{Na}$ sequência das entrevistas efetuadas, identificou-se, também que as empresas envolvidas nesse processo definiram, conjuntamente, que cada uma utilizaria sua própria marca, caracterizando-se, assim, a cooperação (parceria) entre as envolvidas num mercado altamente competitivo. Com isso, nota-se que, independente do segmento, estabeleceuse uma aliança estratégica entre as partes para a produção e distribuição do Arla 32 no Brasil, caracterizando, assim, ações de cooperação descritas pelos respondentes.

\section{Quadro 1: Síntese dos fatores relevantes para o estabelecimento de rede de cooperação}

Fórum para debates sobre os principais riscos e oportunidades desse produto no Brasil entre as empresas atuantes neste projeto, independente do segmento;

Parceria com montadoras para a inclusão da tecnologia SCR nos veículos pesados;

Desenvolvimento conjunto entre as empresas concorrentes para definição dos tipos e tamanhos de embalagens que seriam fornecidas ao mercado;

Aprendizado conjunto dos processos, procedimentos e experiências com empresas de outros países que já trabalham com o Arla 32, mesmo com nomenclaturas diferentes;

Debate entre os gestores que desenvolveram e implantaram a quebra de barreira para que esse produto tivesse entrada no mercado brasileiro, com base na Resolução CONAMA n. ${ }^{\circ} 403$, de 11 de novembro de 2008 e no Programa de Controle da Poluição do Ar por Veículos Automotores (PROCONVE);

Certificação desse produto é obrigatória e conta com a parceria, também, do selo do INMETRO (Instituto Nacional de Metrologia, Qualidade e Tecnologia) e do IBAMA (Instituto Brasileiro do Meio Ambiente e dos Recursos Naturais Renováveis). Essas exigências ocorreram somente para os veículos produzidos a partir de 2012.

\section{Fonte: Elaborado pelos autores.}

No Quadro 1 descreve-se a síntese dos fatores relevantes fundamentados na teoria de Verschoore e Balestrin (2008), para o estabelecimento da rede de cooperação entre os produtores, montadoras, fornecedores de embalagem, postos de combustíveis e órgãos fiscalizadores, que realizaram trabalho com o único objetivo de implantar o Arla 32 no Brasil, em 2012.

Diante do exposto, responde-se ao objetivo geral desta pesquisa voltado a se verificar a existência de coopetição entre empresas no processo de implantação do projeto do Arla 32, pois apresenta, de maneira clara, o conceito de coopetição, que é a cooperação em ambiente competitivo, com objetivo de ganhos mútuos (BRANDENBURGER; NALEBUFF, 1996; LADO; BOYD; HANLON, 1997; GNYAWALI, 2006; WANG; KRAKOVER, 2008). Na Figura 3, um esquema do relacionamento interorganizacional coopetitivo verificado na pesquisa de campo. 


\section{Figura 3: Relacionamento interorganizacional coopetitivo}

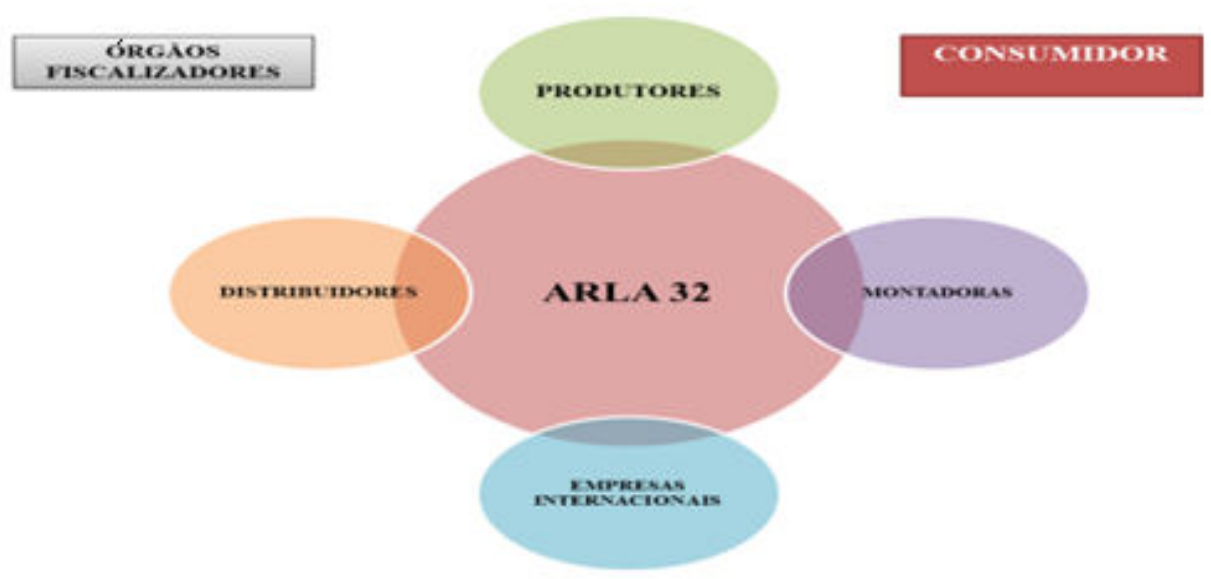

Fonte: Elaborada pelos autores.

Fundamentada nas respostas obtidas dos respondentes, a Figura 3 demonstra o relacionamento interorganizacional coopetitivo verificado, tendo como ponto central o produto Arla 32. Identifica-se a coopetição ao se observar que os produtores, distribuidores, montadoras e empresas internacionais são competidores entre si, estando cada agente em seu respectivo segmento. Porém, esses mesmos agentes cooperam no desenvolvimento e implantação do produto Arla 32 no País, visto que há dependência entre essas empresas para o projeto ser bem-sucedido, o que caracteriza a coopetição. A realidade encontrada no fenômeno analisado nesta pesquisa vai ao encontro das características da coopetição indicadas por Reinl e Kellinher (2010) e Monticelli, Silveira e Silva (2018), que mencionam ações de cooperação entre empresas concorrentes.

Destaca-se a existência de rivalidade entre as partes envolvidas, quanto ao seu posicionamento estratégico, pois, apesar de atuarem em parceria na prospecção de embalagens, estratégias de mercado para definição sobre a distribuição do produto de maneira embalada ou a granel, cada envolvido optou por adquirir sua própria marca, tornando-se, então, competidores diretos no novo mercado. Tal condição é consoante aos resultados identificados nos estudos de Gnyawali e Madhavan (2001) e Gimeno (2004).

Constata-se, ainda, a partir das respostas dos sujeitos entrevistados e das informações divulgadas pelas empresas analisadas, que há também a existência de órgãos fiscalizadores, que envolvem agentes cooperadores na rede de negócios. Esses agentes fiscalizadores não competem com nenhuma empresa envolvida neste projeto. Por fim, há também a figura dos consumidores, considerados como o alvo principal a ser atingido pelas empresas que cooperam na rede de negócios analisada, visando proporcionar o fornecimento do Arla 32 ao mercado consumidor brasileiro. A pluralidade de diferentes agentes e relacionamentos envolvidos na rede de negócios analisada é uma característica também apontada nos estudos de Chen, Chen e Whu (2017) quanto às redes de negócios com características de coopetição.

Dessa maneira, entende-se que há coopetição, ou seja, o relacionamento interorganizacional coopetitivo na implantação do Arla 32 no Brasil, pois, sem tal relacionamento, não seria possível o desenvolvimento com sucesso deste projeto, dada a complexidade de atuação simultânea em diversos segmentos, o que corrobora as teorias de cooperação, competição, coopetição e estratégia abordadas pelos autores expostos no referencial teórico deste trabalho (BRANDENBURGER; NALEBUFF, 1996; LADO; BOYD; HANLON, 1997; BENGTSSON; KOCK; 2000; LEÃO, 2005; GNYAWALI, 2006; WANG; KRAKOVER, 2008). 


\section{CONSIDERAÇÕES FINAIS}

Neste trabalho, analisaram-se quais ações foram realizadas para identificar os relacionamentos interorganizacionais na rede de negócios pesquisada, envolvendo as empresas atuantes no projeto Arla 32 , fundamentadas no conceito da coopetição, que é a consolidação da cooperação com a competição com o objetivo de ganhos mútuos (BRANDENBURGER; NALEBUFF, 1996; LADO; BOYD; HANLON, 1997; BENGTSSON; KOCK; 2000; LEÃO, 2005; GNYAWALI, 2006; WANG; KRAKOVER, 2008).

De acordo com os resultados obtidos na pesquisa empírica, constatou-se que a situação analisada corrobora as teorias de cooperação, a partir do desenvolvimento de relacionamentos interorganizacionais em redes de negócios. O objetivo proposto de se descrever a implantação do produto Arla 32 no País, com foco no desenvolvimento de relacionamentos interorganizacionais em redes de empresas, amparados no conceito da coopetição (cooperação e competição) como estratégia das empresas participantes, foi plenamente alcançado.

O mapeamento das empresas voltadas à produção e distribuição do Arla 32 no País indicou: a Empresa A como líder global que se destacou com a possibilidade de fornecer o produto a granel, proporcionando um novo nicho de mercado; a Empresa B, focada na distribuição e fundamentada numa rede de postos de combustíveis, a qual dividirá essa fatia de mercado com concorrentes de postos com bandeiras diferentes; por fim, a Empresa C, a maior fabricante do produto no Brasil, além de atuar também no segmento de distribuição por meio de produtos embalados.

Constatou-se a existência de ações de cooperação entre as empresas atuantes na rede de negócios voltada à produção e distribuição do Arla 32 no Brasil, notadamente pelo desenvolvimento de relacionamentos interorganizacionais de cooperação. Independentemente da área de atuação, foram verificadas ações de auxílio quanto à infraestrutura, tecnologia, pessoas e atividades complementares em parceria, todas desenvolvidas a partir de um objetivo comum, que era a implantação do produto no Brasil.

Além de se caracterizarem os relacionamentos interorganizacionais de natureza coopetitiva, identificou-se, por meio dos relatos dos respondentes, a necessidade de atuação conjunta entre concorrentes diretos, como o caso dos postos de gasolina envolvidos. Em contrapartida, houve o diagnóstico da coopetição não só no desenvolvimento de embalagens e na distribuição, mas também, principalmente, na definição de cada empresa em atuar no mercado como competidoras diretas, utilizando o agente redutor cada qual com seu posicionamento de marca específico num mesmo ambiente competitivo, possibilitando atender o mesmo público-alvo comum ao dos concorrentes.

Diante do exposto, as principais contribuições desta pesquisa voltam-se para o delineamento das possibilidades da aplicação das teorias que fundamentam os relacionamentos interorganizacionais desenvolvidos em redes coopetitivas. Ou seja, há avanços para a academia, notadamente em relação à corroboração das teorias já desenvolvidas quando houve sua aplicação no contexto específico abordado nesta pesquisa. Não obstante, também são verificadas contribuições às empresas e praticantes, no que tange à aplicabilidade com sucesso dos parâmetros teóricos indicados neste trabalho.

Sugestões para estudos futuros complementares ou extensivos a esta pesquisa indicam a possibilidade de análises idênticas em outros produtos e segmentos de mercado, bem como em outros tipos de redes de negócios, principalmente com ações coopetitivas desenvolvidas por meio de relacionamentos interorganizacionais entre seus membros. Outros trabalhos podem desenvolver uma discussão mais crítica sobre a falta de elementos empíricos mais consistentes a respeito de relacionamentos interorganizacionais coopetitivos.

A pesquisa empírica desenvolvida corroborou as principais características da teoria indicada no referencial teórico, na implantação da produção e distribuição do produto Arla 32 no País. Como contribuição desta pesquisa, salienta-se que 
a coopetição e o desenvolvimento de relacionamentos interorganizacionais coopetitivos são conceitos abrangentes que poderão ser mais bem compreendidos, a partir da situação relatada pelas empresas participantes desta pesquisa, para contribuir com o avanço da compreensão desse complexo fenômeno pela Academia.

\section{REFERÊNCIAS}

AFUAH, A. How much do your "co-opetitors"' Capabilities matter in the face of technological change? Strategic Management Journal, v. 21, n. 3, special issue: Strategic Networks, p. 397-404, mar. 2000.

AFHUJA, G. Colaboration networks, structural holes and innovation: a longitudinal study. Administrative Science Quartely, Sep. 2002.

ANFAVEA. Diesel e emissões: a nova legislação 2012. São Paulo: ANFAVEA, $2012 . \quad$ Disponível em:<http://www.afeevas.org.br/downloads/cartilhaanfaveaproconvep7.pdf>. Acesso em: 15 jul. 2014.

ARMSTRONG, J. S. Co-opetition. Journal of Marketing, v. 61, n. 2, p. 92-99, 1997.

BALESTRIN, A.; VARGAS, L. M. A dimensão estratégica das redes horizontais de PMEs: teorizações e evidências. Revista de Administração Contemporânea (RAC), v. 8, edição especial, p. 203-228, 2004.

BALESTRIN, A.; VERSHOORE, J. Aprendizagem e inovação no contexto das redes de cooperação entre pequenas e médias empresas. Revista da Universidade Federal da Bahia, v.17, n.53, p. 311-330, 2010.

BARDIN, Laurence. Análise de conteúdo. São Paulo: Edições 70, 2011.

BEGNIS, H. S. M.; PEDROZO, E. A.; ESTIVALETE, V. de F. B. Cooperação enquanto estratégia, segundo diferentes perspectivas teóricas. Anais... In: EnANPAD, XXIX, Brasília, 2005.

BENGTSSON, M.; KOCK, S. Cooperation and competition in relationships between competitors in business networks. The Journal of Business \& Industrial Marketing, v. 14, n. 3, p. 178-194, 2000.

BENGTSSON, M.; HINTTU, S.; KOCK, S. Relationships of cooperation and competition between competitors. Proceedings... In: 19th Annual Imp. Conference, Lugano, p. 1-12, 2003.

BENGTSSON, M.; KOCK, S. Coopetition in business networks - to cooperate and compete simultaneously. Industrial Marketing Management, v.29, p.411-426, 2002.

BITTENCOURT, J. Os Arranjos Produtivos Locais (APLs) no Brasil. In: SPOSITO, ES., org. Medidas antidumping e política doméstica: o caso da citricultura estadunidense [online]. São Paulo: UNESP, 2015, pp. 247-263. ISBN 978-85-68334-66-9. Available from SciELO Books.

BOUNCKEN, R. B.; GAST, J.; KRAUS, S.; BOGERS, M.; Coopetition: a systematic review, synthesis, and future research directions. Review of Managerial Science, v. 9, n. 3, p. 577-601, jul. 2015. BRANDENBURGER, A. M.; NALEBUFF, B. J. Coopetição. Rio de Janeiro: Rocco, 1996.

CÂNDIDO, G. A.; ABREU, A. F. Os conceitos de rede e as relações interorganizacionais: um estudo exploratório. Anais... In: XXIV ENANPAD, Florianópolis, 2000.

CASAROTTO FILHO, N.; PIRES, L. H. Redes de pequenas e médias empresas e desenvolvimento local: estratégias para a conquista da competitividade global. 2 ed. São Paulo: Atlas, 2001.

CASSIOLATO, J.E.; LASTRES, H. Globalização \& inovação localizada: experiências em sistemas locais no Mercosul. Brasília, IBICT/MCT, 1999.

CASTELLS, M. A Sociedade em rede. São Paulo: Paz e Terra, 1999.

CASTRO, M.; BULGACOV, S.; HOFFMANN, V. E. Relacionamentos Interorganizacionais e Resultados: Estudo numa Rede de Cooperação Horizontal da Região Central do Paraná. Revista de Administração Contemporânea - RAC, v. 15, n. 1, p. $25-46,2011$.

CHEN, PO-YUAN; CHEN, KUAN-YANG; WU, LEY-WU. The impact of trust and commitment on value creation in asymmetric buyerseller relationships: the mediation effect of specific asset investments. Journal of Business \& Industrial Marketing, v. 32, n. 3., p. 457471, Apr. 2017.

CHIEN, T.; PENG, T. Competition and cooperation intensity in network - A case study in Taiwan simulator industry. Journal of American Academy of Business, v.7, n.2, p.150-155, 2005.

CONAMA. Resolução Conama $\mathrm{n}^{\circ} 403$ de 11 de novembro de 2008 . Disponível em: <http://www.mma.gov.br/port/conama/legiabre.cfm?codlegi=591>. Acesso em: 24 jan 2016.

DAGNINO, G. B.; PADULA, G. Coopetition strategy. A new kind of interfirm dynamics for value creation. Proceedings... In: The European Academy of Management. Estocolmo: Innovative Research in Management, 2002.

FREEMANN, C. Introdução. In: DOSI, G. et al. Technical change and economic theory. London: PrinterPublishers, 1988. 
GIL, A. C. Como elaborar projetos de pesquisa. 4a Ed. São Paulo: Atlas, 2002.

GILBERT JR., D. Co-opetition. Business and Society, v. 37, n. 4, p. 468-476, 1998.

GIMENO, J. Competition within and between networks: the contingent effect of competitive embeddedness on alliance formation. Academy of Management Journal, v.47, n.6, p. 820-842, 2004.

GNYAWALI, D. R.; MADHAVAN, R. Cooperative networks and competitive dynamics: a structural embeddedness perspective. Academy of Management Review, v.26, n.3, p.431-445, 2001.

GRANT, R. M. The resource-based theory of competitive advantage: implications for strategy formulation. California Management Review, v. 33, n. 3, p. 114-135, 1991.

GULATI, R. Alliances and networks. Strategic Management Journal, v.19, n.4, p.293-317, 1998.

GULATI, R.; NOHRIA, N.; ZAHEER, A. Strategic networks. Strategic Management Journal, v. 21, p. 203-215, 2000.

HAGEDOORN, J. Inter-firm R\&D partnerships: an overview of major trends and patterns since 1960. Research Policy, n.31, p.477-492, 2002.

HITT, M. A.; IRELAND, R. D.; HOSKISSON, R. E. Administração estratégica. São Paulo: Thomson Learning, 2002.

HOFFMANN, V. E.; MOLINA-MORALES, F. X.; MARTINEZ-FERNANDEZ, M. T. Redes de empresas: uma proposta de tipologia para sua classificação. Anais... In: ENANPAD, XVIII, Curitiba, 2004.

HUMPHREY, J.; SCHMITZ, H. Trust and inter-firm relations in developing and transition economies. IDS-Univ. of Sussex, 1998.

JAOEN, A.; GUNDOLF, K. Strategic alliances between microfilms, specific patterns in the French context. International Journal of Entrepreneurial Behaviour \& Research, v.15, n.1, 2009.

JORDE, T. M.; TEECE, D. J. Competition and cooperation: striking the right balance. California Management Review, v.31, n.3, p.25-37, Spring 1989.

LADO, A.A.; BOYD, N.G.; HANLON, S.C. Competition, cooperation, and the search for economic rents: a syncretic model. Academy of Management Review, v. 22, n.1, p. 110-141, jan. 1997.

LEÃO, D. A. F. S. Relevância da teoria da coopetição para a compreensão da dinâmica dos relacionamentos entre empresas concorrentes. Anais... In: XXIXENANPAD, Brasília, 2005.

LIPNACK, J.; STAMPS, J. Rede de informações. São Paulo: Makron Books, 1994.

MACHADO FILHO, C. A. P.; ZYLBERSZTAJN, D. A Empresa socialmente responsável: O debate e as implicações. RAUSP, v.39, n. 3, p. 242-254, 2004.

MATURANA, H. R.; VARELA, F. J. A árvore do conhecimento: as bases biológicas da compreensão humana. São Paulo: Pala-Athenas, 1987.

MICHEL, M. H. Metodologia e pesquisa científica em ciências sociais. São Paulo: Atlas,2009.

MILES, R. E.; SNOW, C. C. Network organizations: new concepts for new forms. California Management Review, v.28, n.3, p.62-73, 1986.

MONTICELLI, J. M.; SILVEIRA, A. B. da.; SILVA, L. M. da. The process of competitive strategy: A case study of microbreweries in Porto Alegre. Revista de Administração Mackenzie, v. 19, n. 4, p. 1-32, 2018.

OLSON, M. The logic of collective action: public goods and the theory of groups. Cambridge: Harvard University Press, 1971.

PEREIRA, C.G.; SILVA, R.R. da; LAVOIE, J.R.; PORTO, G. S. Technological cooperation network in biotechnology Analysis of patents with Brazil as the priority country. Innovation \& Management Review, v. 15, n. 4, p. 416-434, 2018.

PERROW, C. Small-firms networks. In: NOHRIA, N.; ECCLES, R. (Orgs.). Networks and organizations: structure, form and action. Boston: Harvard Business School Press, 1992.

QUINN, J. B.; ANDERSON, P.; FINKELSTEIN, S. New forms of organizing. The Academy of Management Review, v. 22, n. 4, p. 887910, 1997.

REINL, L.; KELLIHER, F. Cooperative micro-firm strategies: leveraging resources through learning networks. International Journal of Entrepreneurship and Innovation, v. 11, n. 2, p.141-158, 2010.

RESENDE, L. M. M.; VOLSKIB, I.; BETIM, L. M.; CARVALHO, G. D. G. de.; BARROS, R. de.; SENGERF, F. P. Critical success factors in coopetition: Evidence on a business network. Industrial Marketing Management, v. 68, p. 177-187, jan. 2018.

RODRIGUES, L. C.; MACCARI, E.A.; RISCAROLLI, V. Arquitetura e Coopetição em Redes Organizacionais. Journal of Information Systems and Technology Management, v. 4, n.2, p. 175-196, 2007.

SAMPIERI, R. H.; COLLADO, C. R; LÚCIO, P. B. Metodologia de pesquisa. 5 ed. São Paulo: McGraw Hill, 2013.

SANTOS, S. A.; PEREIRA, H. J.; ABRAHÃO FRANÇA, S. E. Cooperação entre micro e pequenas empresas. São Paulo: Sebrae, 1994. 
SACOMANO NETO, M.; TRUZZI, O. M. S. Perspectivas contemporâneas em análise organizacional. Revista Gestão e Produção, v.9, n.1, p. 32-44, abr. 2002

TRIVINOS, A.N.S. Introdução à pesquisa em ciências sociais: a pesquisa qualitativa em educação. São Paulo: Atlas, 1987.

UZZI, B. Social structure and competition in interfirm networks, the paradox of embeddedness. Administrative Science Quarterly, p. 3567, 1997.

VERSCHOORE, J.R.(Org.). Redes de cooperação: uma nova organização de pequenas emédias empresas no rio grande do sul. Porto Alegre: FEE, 2004.

VERSCHOORE, J.R.; BALESTRIN, A. Ganhos competitivos das empresas em redes de cooperação. RAUSP, v.1, n.1, 2008.

WANG, Y.; KRAKOVER, S. Destination marketing: competition, cooperation or coopetition? International Journal of Contemporary Hospitality Management, v. 20, n. 2, p. 126-141, 2008.

WEBER, M. Ensaios de sociologia. Rio de Janeiro: J. Zahar, 1982.

WILLIAMSON, O. E. The economic institutions of capitalism. New York: The Free Press, 1985.

ZACCARELLI, S. B. Estratégia e sucesso nas empresas. São Paulo: Saraiva, 2005. 